\title{
Diabetic Foot Among Elderly at Zagazig City: Risk Factors and Foot Care Practices
}

\author{
Eman Shokry Abd-Allah ${ }^{1}$, Sabah Abdou Hagrass ${ }^{2}$, Shimaa Salah Mohamed ${ }^{3}$ \\ ${ }^{1}$ Gerontological Nursing Department, Faculty of Nursing, Zagazig University, Zagazig City, Egypt \\ ${ }^{2}$ Community Health Nursing Department, Faculty of Nursing, Zagazig University, Zagazig City, Egypt \\ ${ }^{3}$ Department of Community Health Nursing, Faculty of Nursing, Zagazig University, Zagazig City, Egypt
}

\section{Email address:}

emanshokry2012@yahoo.com (E. S. Abd-Allah)

\section{To cite this article:}

Eman Shokry Abd-Allah, Sabah Abdou Hagrass, Shimaa Salah Mohamed. Diabetic Foot Among Elderly at Zagazig City: Risk Factors and Foot Care Practices. American Journal of Nursing Science. Vol. 5, No. 1, 2016, pp. 22-29. doi: 10.11648/j.ajns.20160501.14

\begin{abstract}
Background: Foot health problems are common in the elderly due to pathological changes in their feet. The aim of this study was to identify diabetic foot risk factors among the elderly at Zagazig City Subjects and methods; Analytic cross sectional study design was utilized. The study was conducted at Zagazig health insurance clinic for the elderly diabetic patients with purposive sample composed of (280) of the elderly diabetic patients. Tools, tool I, Interview questionnaire sheet composed of four parts (socio demographic characteristics, medical past \&present history of diabetes, assessing patient foot care practice and assessment of risk factors of diabetic foot) and tool II, physical assessment of diabetic foot condition. Results it revealed that approximately one-half of the patients were 60-65 years old, only more than the third of studied patients had adequate foot care practice; the foot inspection revealed that the majority of them had abnormal foot and statistically significant relations between patients practice and their level of education, job type and income. The foot inspection revealed that the patients had no infection, no ulcer and no low blood flow had a higher percentage of normal examination. Conclusion The study found several factors associated with higher incidence of diabetic foot among the elderly diabetic patients including: low educational level, longer duration of diabetes, smoker, lack of foot care and poor footwear. Recommendations: Educate diabetic patients, about diabetic foot care practice through educational program to reduce the risk of complications.
\end{abstract}

Keywords: Risk Factors, Diabetic Foot, Elderly, Foot Care Practices

\section{Introduction}

Worldwide, people aged 65 years or more are estimated to represent around $30 \%$ of the population in the next 20 years (Kangas et al., 2011). In Egypt, the number of elderly persons reached 5.8 million in 2011, representing $7.3 \%$ of total population (Central Agency for public Mobilization and Statistics [CAMAS], 2011). Aging is associated with a wide range of physiological changes that increase the susceptibility to a number of diseases, including diabetes (Lopez-Otin et al., 2013).

One important complication of DM is the foot problems, which constitute a leading cause of hospital admission, amputation and mortality in diabetic patients (Desalu et al., 2011; Moxey et al., 2011). Foot health problems are common in the elderly due to pathological changes in their feet, difficulties involved in taking care of their extremities (Barr et al., 2007). The prevalence of diabetic foot ulceration in the diabetic population is $4-10 \%$; the condition is more frequent in older patients (Lauterbach et al., 2013). The risk factors that increase the risk of diabetic foot include inappropriate footwear, damage of peripheral nerves, poor circulation, trauma, and smoking (Groner, 2010; Mendes and Neves, 2012).

Proper foot self-care practice is crucial for long-term survival and wellbeing of diabetic patients (Rocha et al., 2009). Treating existing foot issues, routinely taking care of one's feet, visiting a podiatrist annually to make foot assessments is also important (Rajna and Alison 2006). Hence, multidisciplinary interventions to increase patients' knowledge about foot care, podiatry, and therapeutic shoes, can improve the condition of the feet and help to reduce ulcer and amputation rates (Louise and Russell, 2009). The goal of Gerontology nursing is crucial here to promote optimal health for older persons, and maximize independence by identifying the strengths of the older person and enhancing or maintaining these strengths (National Institute of Neurological Disorders and Stroke [NINDS], 2011). They can educate patients to carry out simple rules to prevent foot 
ulcers or recurrence, such as checking the shoes before wearing, keeping feet clean and continuing care of the skin and nails (Peterman, 2010).

Hence, diabetic foot constitutes a major health problem with negative impacts on the patient, family members, and the community. Patients with diabetes need an annual foot screening to enable nurses to establish baseline data, which help in tracking high-risk patients, reduce modifiable risk factors, and plan patient frequency of follow-up. This would lead to decrease cost of care and improve the quality of care provided.

\subsection{Significance of the Study}

Diabetic foot constitutes a major health problem with serious consequences. It may have negative impacts on the patient, family members, and the community in large. Patients with diabetes need an annual foot screening to enable the nurse to establish baseline data which help her to track high risk patients, reduce modifiable risk factors, and plan patient frequency of follow-up. Specialist referral and screening may aid in identification of new undiagnosed foot problems, and there is a need for focal point that would be the base for regular treatment, as well as prevention by early detection of diabetic foot problem. This leads to decrease cost of care and improve the quality of care provided by hospital team.

\subsection{Aim of the Study}

The aim of this study was to identify diabetic foot risk factors and foot care practices among the elderly at Zagazig City.

\section{Subjects and Methods}

Research design and setting: This analytic cross-sectional was conducted at the health insurance comprehensive clinic for elderly diabetic patients at Zagazig city.

Subjects: Any elderly patient attending the study setting during the study period was eligible if aged 60 to 80 years, diagnosed as diabetic patient, fully dependent, and able to participate. The sample size was calculated using the software program Epi-Info version 6.04 to estimate any risk factor of diabetic foot with $20 \%$ prevalence or higher at $95 \%$ level of confidence and with a $4 \%$ absolute precision. The required sample size was 280 after taking into account a non-response rate of about $10 \%$. The participants were recruited consecutively according to set criteria.

\subsection{Tools for Data Collection}

The data collection tools included an interview questionnaire sheet and a physical examination checklist. The interview questionnaire covered the participant's sociodemographic characteristics, medical history, and risk factors of diabetic foot such as lack of sensation, smoking and foot infection. The last part was intended to assess the patient's practice of foot care, based on Chellan et al (2012). It consists of 10 questions such as inspecting feet daily, cutting nails carefully, washing feet daily, etc. The answer to every question was "yes," "sometimes," or "no," scored 2, 1, and zero respectively. The points were summed-up and converted into a percent score. A patient getting $60 \%$ or more of the total score was considered as having adequate practice of foot care.

The physical examination checklist was developed by the National Foot Care Project [NFCP], (2003) for assessing basic foot condition. It consists of five main items covering neuropathy symptoms, inspection of foot, checking foot pulses, examining foot sensation, and assessment of footwear. Each item is checked as "present" or "absent," scored 1 and zero respectively. The points were summed-up and converted into a percent score so that a higher score indicates a higher number of abnormal findings. A patient getting $60 \%$ or more of the total score was considered as having abnormal physical assessment, and normal if less than $60 \%$.

The validity of the tools was assessed by seven experts from Community Health Nursing and Geriatric Nursing, in addition to medical staff who reviewed the tools content for clarity, relevance, comprehensiveness, and understandability. The reliability of the scale of foot care practice was assessed in a pilot study; it showed good reliability with Cronbach alpha coefficient 0.76 .

\subsection{Fieldwork}

Upon obtaining official approvals through appropriate channels, the researchers visited the outpatient clinics in the study settings. They met with the elderly patients and recruited those who fulfilled the eligibility criteria. Those who agreed to participate were interviewed and were subject to physical assessment. The fieldwork extended from March to June 2014.

\subsection{Ethical Considerations}

The study protocol was approved by the research and ethics committee at the Faculty of Nursing, Zagazig University. The aim of the study was explained to the subjects. Their verbal consent to participate in the study was obtained after informing them about their right to refuse or withdraw at any time. The confidentiality of any obtained information was insured and the data were used only for research purpose. The study procedures could not lead to any actual or potential harmful effects on participants.

\subsection{Statistical Analysis}

Data entry and statistical analysis were done using SPSS 18.0 statistical software package. Cronbach alpha coefficient was calculated to assess the reliability of the used scale. Spearman rank correlation was used for assessment of the inter-relationships among quantitative variables and ranked ones. In order to identify the independent predictors of the scores of practice and physical assessment multiple linear regression analysis was used after testing normality, and homoscedasticity, and analysis of variance for the full regression models was done. Statistical significance was considered at $\mathrm{p}$-value $<0.05$. 


\section{Results}

Table 1 illustrates that approximately one-half of the patients were 60-65 years old (49.6\%), with slightly more males $(55 \%)$. More than two-thirds were married $(70.7 \%)$ and from rural areas (72.9\%). As regards their education, almost one-third of them were illiterate $(31.1 \%)$, and an additional $22.5 \%$ were just able to read and write. The majority of the patients was not working (74.3\%). The table also demonstrates that the majority were living in a crowding index of $<2(75 \%)$, with their families $(86.4 \%)$, and had their own source of income $(87.1 \%)$, which was sufficient $(62.5 \%)$, and $62.5 \%$ had their treatment fees paid by the government. Approximately one-fourth of the patients in the study sample were smoking (24.6\%).

Table 1. Socio-demographic characteristics of patients in the study sample $(n=280)$.

\begin{tabular}{|c|c|c|}
\hline Socio-demographic characteristics & Frequency & Percent \\
\hline \multicolumn{3}{|l|}{ Age: } \\
\hline $60-65$ & 139 & 49.6 \\
\hline $66-70$ & 96 & 34.3 \\
\hline $71-80$ & 45 & 16.1 \\
\hline \multicolumn{3}{|l|}{ Gender: } \\
\hline Male & 154 & 55.0 \\
\hline Female & 126 & 45.0 \\
\hline \multicolumn{3}{|l|}{ Marital status: } \\
\hline Married & 198 & 70.7 \\
\hline Divorced/widow & 82 & 29.3 \\
\hline \multicolumn{3}{|l|}{ Residence: } \\
\hline Rural & 204 & 72.9 \\
\hline Urban & 76 & 27.1 \\
\hline \multicolumn{3}{|l|}{ Education: } \\
\hline Illiterate/ & 87 & 31.1 \\
\hline Read/write & 63 & 22.5 \\
\hline Basic/ Intermediate & 62 & 22.1 \\
\hline Higher & 68 & 24.3 \\
\hline \multicolumn{3}{|l|}{ Job: } \\
\hline Clerical & 16 & 5.7 \\
\hline Manual & 56 & 20.0 \\
\hline Retired/not working & 208 & 74.3 \\
\hline \multicolumn{3}{|l|}{ Crowding index: } \\
\hline$<2$ & 210 & 75.0 \\
\hline $2+$ & 70 & 25.0 \\
\hline \multicolumn{3}{|l|}{ Live: } \\
\hline With family & 242 & 86.4 \\
\hline Alone & 38 & 13.6 \\
\hline \multicolumn{3}{|l|}{ Income source: } \\
\hline Own & 244 & 87.1 \\
\hline Aid & 36 & 12.9 \\
\hline \multicolumn{3}{|l|}{ Income: } \\
\hline Insufficient & 60 & 21.4 \\
\hline Sufficient & 175 & 62.5 \\
\hline Saving & 45 & 16.1 \\
\hline \multicolumn{3}{|l|}{ Treatment fees by government: } \\
\hline No & 105 & 37.5 \\
\hline Yes & 175 & 62.5 \\
\hline Smoking & 69 & 24.6 \\
\hline
\end{tabular}

Concerning the history of diabetes (Table 2), more than one-third of the patients had the disease for 15 years or more $(37.5 \%)$. The most frequently reported symptoms were polyuria $(71.1 \%)$ and thirst $(66.1 \%)$, whereas only $2(0.7 \%)$ patients reported having dysuria. Insulin was the most commonly used medication $(73.6 \%)$, while $16.8 \%$ of the patients depended on diet and $3.6 \%$ on exercise. Less than two thirds of the patients knew their medications (60.7\%), but only $15 \%$ were having a DM ID card. The majority of patients had DM complications (88.9\%). Almost all patients had previous attacks of hyperglycemia (95.4\%), while $39.3 \%$ had previous hypoglycemia.

Table 2. Characteristics of diabetes disease among patients in the study sample $(n=280)$.

\begin{tabular}{|c|c|c|}
\hline Characteristics of diabetes disease & Frequency & Percent \\
\hline \multicolumn{3}{|l|}{ Duration of diabetes (years): } \\
\hline$<5$ & 36 & 12.9 \\
\hline $5-$ & 62 & 22.1 \\
\hline $10-$ & 77 & 27.5 \\
\hline $15+$ & 105 & 37.5 \\
\hline \multicolumn{3}{|l|}{ Symptoms: @ } \\
\hline Polyuria & 199 & 71.1 \\
\hline Thirst & 185 & 66.1 \\
\hline Delayed wound healing & 128 & 45.7 \\
\hline Loss of weight & 118 & 42.1 \\
\hline Loss of appetite & 58 & 20.7 \\
\hline Increased appetite & 56 & 20.0 \\
\hline Coma & 38 & 13.6 \\
\hline Dysuria & 2 & 0.7 \\
\hline \multicolumn{3}{|l|}{ Treatment used: ${ }^{@}$} \\
\hline Oral & 124 & 44.3 \\
\hline Insulin & 206 & 73.6 \\
\hline Diet & 47 & 16.8 \\
\hline Exercise & 10 & 3.6 \\
\hline \multicolumn{3}{|l|}{ No. of treatments: } \\
\hline 1 & 187 & 66.8 \\
\hline 2 & 80 & 28.6 \\
\hline $3+$ & 13 & 4.7 \\
\hline Know medications & 170 & 60.7 \\
\hline Has DM ID card & 42 & 15.0 \\
\hline Has DM complications & 249 & 88.9 \\
\hline Had previous hypoglycemia & 110 & 39.3 \\
\hline Had previous hyperglycemia & 267 & 95.4 \\
\hline
\end{tabular}

(@) Not mutually exclusive

Table 3. Risk factors of foot problems among patients in the study sample $(n=280)$.

\begin{tabular}{lll}
\hline Risk factors & Frequency & Percent \\
\hline Check blood sugar regularly & 115 & 41.1 \\
Has regular follow-up & 110 & 39.3 \\
Examine feet sensation regularly & 56 & 20.0 \\
Has low blood flow in feet & 119 & 42.5 \\
Has sensory loss in feet & 95 & 33.9 \\
Has feet ulcers & 140 & 50.0 \\
Has foot infection & 164 & 58.6 \\
Ever had foot gangrene & 78 & 27.9 \\
Has foot anomalies & 67 & 23.9 \\
Has visual problems & 170 & 60.7 \\
Has hypertension & 124 & 44.3 \\
\hline
\end{tabular}

According to Table 3 , only $41.1 \%$ of the patients were checking their blood sugar regularly, 39.3\% had regular follow-up, and a lower percentage examined their feet sensation regularly (20\%). Half of them had feet ulcers, and approximately two-thirds had foot infection (58.6\%). Moreover, $27.9 \%$ of the patients had had foot gangrene, and $60.7 \%$ had visual problems.

Table 4 describes patients' foot care habits. It shows that only washing feet daily was practiced by $61.5 \%$ of the patients. Other practices were seldom reported by patients, 
particularly changing footwear regularly (16.4\%), keeping blood pressure under control $(18.9 \%)$, moisturizing dry areas of the feet daily (25.4\%), daily checking feet for injury $(28.2 \%)$, and never walking barefoot $(28.2 \%)$.

Table 4. Foot care practice among patients in the study sample $(n=280)$.

\begin{tabular}{|c|c|c|c|c|c|c|}
\hline \multirow{2}{*}{ Foot care practices } & \multicolumn{2}{|l|}{ No } & \multicolumn{2}{|c|}{ Sometimes } & \multicolumn{2}{|l|}{ Yes } \\
\hline & No. & $\%$ & No. & $\%$ & No. & $\%$ \\
\hline Wash feet daily & 9 & 3.2 & 99 & 35.4 & 172 & 61.4 \\
\hline Moisturize dry areas of feet daily & 108 & 38.6 & 101 & 36.1 & 71 & 25.4 \\
\hline Check feet daily for any injury & 72 & 25.7 & 129 & 46.1 & 79 & 28.2 \\
\hline $\begin{array}{l}\text { Proper action in case of any } \\
\text { abnormality on feet }\end{array}$ & 33 & 11.8 & 114 & 40.7 & 133 & 47.5 \\
\hline Cut toe nails straight regularly & 48 & 17.1 & 147 & 52.5 & 85 & 30.4 \\
\hline $\begin{array}{l}\text { Check whether shoes/socks leave } \\
\text { marks on feet }\end{array}$ & 60 & 21.4 & 118 & 42.1 & 102 & 36.4 \\
\hline Change footwear regularly & 203 & 72.5 & 31 & 11.1 & 46 & 16.4 \\
\hline Go for foot checkup & 160 & 57.1 & 69 & 24.6 & 51 & 48.2 \\
\hline Never go barefoot even at home & 41 & 14.6 & 160 & 57.1 & 79 & 28.2 \\
\hline $\begin{array}{l}\text { Keep blood sugar under control } \\
\text { with proper eating, activity, and } \\
\text { medicine if needed }\end{array}$ & 115 & 41.1 & 112 & 40.0 & 53 & 18.9 \\
\hline
\end{tabular}

The foot assessment (Table 5) shows that the most common neuropathic problems were rest pain $(52.1 \%)$ and intermittent claudications (46.4\%). Foot inspection revealed that $60.7 \%$ of the patients had infection, and $38.6 \%$ had ulcerations. The table also indicates that the pulse was absent in the dorsalis pedis of $10.7 \%$ of the patients and in the posterior tibial of $14.3 \%$ of them. Also, $18.2 \%$ had complete loss of sensation. Meanwhile, the footwear was normal, suitable, and good in approximately two-thirds of the patients.

Table 6 demonstrates a statistically significant moderate negative correlation between patients' scores of practice and their abnormal feet assessment findings $(\mathrm{r}=-0.448)$; weak negative correlations with their crowding index, duration of diabetes, and previous hypo/hyperglycemic attacks; and weak positive correlations with their age, income and number of treatments. As for the abnormal feet assessment findings score, it had a statistically significant moderate positive correlation with the previous hypoglycemic attacks $(\mathrm{r}=0.448)$; and weak positive correlations with their age, number of complications, and previous hyperglycemic attacks; and weak negative correlations with their education, and number of treatments.

In multivariate analysis (Table 7), the statistically significant positive predictors of patients' practice score were the level of education, checking blood sugar, and the number of treatments. On the contrary, living alone, having a family history of DM, and smoking were negative predictors. The regression model explains $25 \%$ of the variation in the practice score. Concerning the score of abnormal feet assessment findings, the table indicates that the duration of diabetes and the complications were statistically significant positive predictors whereas the number of treatments and the practice score were negative predictors. The model explains $27 \%$ of the variation in the practice score.

Table 5. Basic foot assessment among patients in the study sample $(n=280)$.

\begin{tabular}{|c|c|c|}
\hline Basic foot assessment & Frequency & Percent \\
\hline \multicolumn{3}{|l|}{ Neuropathic assessment: } \\
\hline Rest pain & 146 & 52.1 \\
\hline Intermittent claudication & 130 & 46.4 \\
\hline Previous foot ulcer & 111 & 39.6 \\
\hline Amputation & 100 & 35.7 \\
\hline Neuropathic symptoms & 87 & 31.1 \\
\hline \multicolumn{3}{|l|}{ Feet inspection: } \\
\hline Infection & 170 & 60.7 \\
\hline Ulceration & 108 & 38.6 \\
\hline Nail disorder & 100 & 35.7 \\
\hline Skin breaks & 69 & 24.6 \\
\hline Calluses or corns & 46 & 16.4 \\
\hline \multicolumn{3}{|l|}{ Foot pulses: } \\
\hline \multicolumn{3}{|l|}{ Dorsalis pedis: } \\
\hline Present & 153 & 54.6 \\
\hline Weak & 97 & 34.6 \\
\hline Absent & 30 & 10.7 \\
\hline \multicolumn{3}{|l|}{ Posterior tibial: } \\
\hline Present & 137 & 48.9 \\
\hline Weak & 103 & 36.8 \\
\hline Absent & 40 & 14.3 \\
\hline \multicolumn{3}{|c|}{ Test for neuropathy (monofilament) } \\
\hline Intact sensation & 117 & 41.8 \\
\hline Paresthesia & 55 & 19.6 \\
\hline Dyesthesia & 57 & 20.4 \\
\hline Complete loss of sensation & 51 & 18.2 \\
\hline \multicolumn{3}{|l|}{ Assess footwear: } \\
\hline Style (normal) & 194 & 69.3 \\
\hline Condition (good) & 197 & 70.4 \\
\hline Fit (suitable) & 191 & 68.2 \\
\hline
\end{tabular}

Table 6. Correlation between patients' practice of foot care and foot examination and their socio-demographic and disease characteristics.

\begin{tabular}{lll}
\hline & \multicolumn{2}{l}{ Spearman's rank correlation coefficient } \\
\cline { 2 - 3 } & Foot care practice score & \multicolumn{1}{c}{ Abnormal assessment score } \\
\hline Abnormal assessment score & $-.448^{* *}$ & $.135^{*}$ \\
Age & $-.143^{*}$ & $-.225^{* *}$ \\
Education & $.317^{* *}$ & 0.08 \\
Crowding index & $-.150^{*}$ & $-129 *$ \\
Income & $-.158^{* *}$ & -0.09 \\
Duration of DM & $.224^{* *}$ & $.357^{* *}$ \\
No. of treatments & -0.10 & $-.256^{* *}$ \\
No. of complications & $-.344^{* *}$ & $.217^{* *}$ \\
Previous hypoglycemic attacks & $-.128^{*}$ & $.448^{* *}$ \\
Previous hyperglycemic attacks & $.314^{* *}$ \\
\hline
\end{tabular}

(*) Statistically significant at $\mathrm{p}<0.05(* *)$ Statistically significant at $\mathrm{p}<0.01$ 
Table 7. Best fitting multiple linear regression model for the practice and abnormal assessment findings scores.

\begin{tabular}{|c|c|c|c|c|c|c|c|}
\hline & \multicolumn{2}{|c|}{ Unstandardized Coefficients } & \multirow{2}{*}{$\begin{array}{l}\text { Standardized } \\
\text { Coefficients }\end{array}$} & \multirow{2}{*}{ t-test } & \multirow{2}{*}{ p-value } & \multicolumn{2}{|c|}{ 95\% Confidence Interval for B } \\
\hline & B & Std. Error & & & & Lower & Upper \\
\hline \multicolumn{8}{|c|}{ Foot care practice score } \\
\hline Constant & 45.41 & 5.35 & & 8.49 & $<0.001$ & 34.87 & 55.95 \\
\hline Education & 3.39 & 0.66 & 0.31 & 5.13 & $<0.001$ & 2.09 & 4.68 \\
\hline Live alone & -6.37 & 3.16 & -0.11 & -2.01 & 0.045 & -12.60 & -0.14 \\
\hline Family history & -5.92 & 2.27 & -0.15 & -2.61 & 0.010 & -10.39 & -1.46 \\
\hline Check blood sugar & 6.06 & 2.32 & 0.15 & 2.62 & 0.009 & 1.50 & 10.63 \\
\hline No. of treatments & 7.21 & 1.95 & 0.21 & 3.70 & $<0.001$ & 3.37 & 11.04 \\
\hline Smoking & -11.63 & 2.59 & -0.25 & -4.49 & $<0.001$ & -16.72 & -6.53 \\
\hline \multicolumn{8}{|c|}{$\begin{array}{l}\mathrm{r} \text {-square }=0.25 \text { Model ANOVA: } \mathrm{F}=13.059, \mathrm{p}<0.001 \text {. Variables entered and excluded: age, sex, job, crowing index, income, marital status, residence, fees, } \\
\text { DM duration, hypo/hyperglycemic attacks complications. } \\
\text { Abnormal feet assessment findings score }\end{array}$} \\
\hline Constant & 3.43 & 0.41 & & 8.31 & $<0.001$ & 2.61 & 4.24 \\
\hline DM duration & 0.05 & 0.01 & 0.22 & 4.03 & $<0.001$ & 0.02 & 0.07 \\
\hline No. of treatments & -0.34 & 0.15 & -0.13 & -2.35 & 0.020 & -0.63 & -0.06 \\
\hline No. of complications & 0.21 & 0.07 & 0.18 & 3.29 & 0.001 & 0.09 & 0.34 \\
\hline Practice score & -0.02 & 0.00 & -0.33 & -5.76 & $<0.001$ & -0.03 & -0.02 \\
\hline
\end{tabular}

\section{Discussion}

Diabetic foot problems remain a major issue among elderly patients with diabetes. The aim of this study was to identify diabetic foot risk factors among the elderly at Zagazig City through assessing the risk factors of the elderly patients with diabetic foot, evaluating the practices related to diabetic foot care among them, and assessing their foot condition. The study findings point to generally high prevalence of DM-related complications, along with lack of regular follow-up and inadequate foot self-care practices. These practices as well as the foot problems are influenced by patients' personal and disease characteristics.

The study was carried on a sample of elderly patients with diabetes attending the health insurance clinic at Zagazig city. This is a specialized center providing diabetic care for the elderly in the study setting. In fact, most of the management of diabetes is currently provided in primary health care centers through general practitioners and family physicians. This is the current trend all over the world such as Germany (Busetto et al, 2015), Australia (Tran et al, 2015), and Italy (Nicolucci et al, 2015). Thus, a study in Pennsylvania, United States, showed that the provision of DM management in primary care settings led to better service regarding access to service, medication prescription, and health education counselling (Losby et al, 2015). Moreover, integrating nursing in a multidisciplinary team in these settings had a significant positive impact on diabetic quality indicators as well as on patient satisfaction (Biernacki et al, 2015).

A considerable percentage of the patients in the current study, more than one-third, had their diabetes for 15 years or longer. This long disease duration could explain the relatively high prevalence of DM-related complications among them. It is known that the complications of diabetes, especially the neurovascular problems increase with advancing age. In fact, the neurological complications such as leg pains and optic neuropathy were the most frequently reported by these patients. The findings are in line with those of Al-Sayah et al
(2015) in Canada, where the most commonly reported complications of DM were neuropathy and vasculopathy.

The majority of the patients in the present study approximately three-fourth - were using insulin therapy for their diabetes. This is quite expected given the type and duration of their diabetes. However, the use of insulin may increase the risk of diabetic foot complications. In agreement with this, a recent cohort study in China identified insulin as an independent risk factor for foot ulceration among diabetic patients (Jiang et al, 2015).

As regards patients' compliance and adherence to medications and follow-up, the current study results revealed that approximately two-fifth of them did not know their medications, and a majority had no regular checkup of their blood glucose. Moreover, only a few of them had a DM identification (ID) card. The findings point to a major deficiency in these patients' health care practices that need to be addressed by their providers. In congruence with this, a study in India revealed low adherence to diabetes management among type-2 DM patients, and this was attributed to their lack of related knowledge (Chavan et al, 2015). On the same line, a study in Italy showed that only approximately $40 \%$ of the patients were adherent to their medications (Napolitano et al, 2015).

Almost all patients in the present study experienced at least one attack of hyperglycemia, reflecting a lack of good control. Concerning the history of hypoglycemia, a lower percentage of patients in the current study - approximately two-fifth - reported having had it at least once. This is a serious complication of DM, which is considered as a medical emergency. Its occurrence with this relatively high prevalence in the study sample reflects poor control of diabetes. Thus, both conditions need to be prevented especially in elderly patients. In agreement with this, $D u$ et al (2014) in Taiwan stressed that both severe hypoglycemia and persistent hyperglycemia are deleterious to older adults with T2DM, and both conditions should be avoided.

The present study investigated the practice of foot self-care among elderly diabetic patients, which proved to be low. This 
might be related to the patients themselves or their living conditions, or the health care providers. In agreement with this finding, Al-Sayah et al (2015) in a study carried out in Canada on adult patients with type-2 DM showed that the practice of self-care was low particularly in foot self-care. However, other important practices were not done by the patients in the present study; some probably for economic reasons such as changing footwear more than once per year, while others could be attributed to the level of health literacy such as keeping blood pressure under control. On the other hand, some missed practices would not cost any money or need any health literacy, such as daily checking feet for injury, and never walking barefoot. These costless practices would save elderly diabetic patients lot of direct and indirect costs. In line with this, Buysman et al (2015) and Stuart et al (2015) in the United States found that adherence to medications only would lead to significant reductions in healthcare costs.

Certain patients' characteristics seem to influence their practice of foot care in the present study. For instance, the patients with higher level of education, with clerical jobs, and sufficient income had significantly better practice. This indicates that a higher socio-economic level is reflected on better health behavior. The relation with education was confirmed through multivariate analysis. In agreement with this, a recent study in the United Arab Emirates revealed that illiteracy was a significant risk factor for foot complications among diabetics (Al-Kaabi et al, 2015). Living with family was another factor with positive influence on patient's practice in the current study. This might be explained by the support patients get from their families in adhering to healthy practices. In line with this, studies in Iran (Khosravizade Tabasi et al, 2014) and in the United States (Mayberry and Osborn, 2014) showed the positive effect of family support in diabetic patients' self-care practices.

The present study has also shown that the patients who were smoking significantly less adequate practice, which was also confirmed through multivariate analysis. This is quite expected since smoking reflects a risky health behavior. A similar negative effect of smoking on self-care behaviors among type-2 DM patients was reported from a study in Australia (Skinner et al, 2014). Moreover, the current study multiple regression analysis confirmed the independent positive effect of regular checking of blood glucose on patients' practice of foot self-care. In agreement with this, a study in Iran revealed that foot self-care practices were better among diabetic patients practicing regular blood glucose testing, and having high self-efficacy (Tol et al, 2012a).

The present study assessed the foot condition of the elderly patients with diabetes. The findings indicated that almost all of them had at least one abnormal finding on inspection. The most commonly observed problems were infections and ulcerations, in addition to absence of pulses in peripheral arteries, and complete loss of sensation. These are the most common manifestations of diabetic foot, and their high prevalence indicates lack of proper diabetic control. Similar high prevalence of diabetic foot and associated complications were found in a study in China (Wu et al, 2015). Even higher prevalence rates were reported in a study carried out in the

\section{Eastern Caribbean region (Islam et al, 2013).}

Lastly, the present study demonstrated that patients' adequate practice of foot self-care was associated with lower rates of feet abnormal findings and this was confirmed through multivariate analysis. The finding demonstrates the importance of improving patients' practice of foot self-care in the prevention of diabetic foot complications. In congruence with this, a study in Korea demonstrated the beneficial effects of improving the knowledge and self-management practices of type-2 DM patients on their health behavior and disease outcomes (Shin et al, 2015). Additionally, the current study identified the duration of diabetes and the number of complications as the significant risk factors for the abnormal assessment score indicating diabetic foot. Conversely, the number of treatments and the score of practice of foot selfcare were protective factors. In agreement with this, a study in Saudi Arabia revealed that the foot complications increased with the duration of the disease (Al-Rubeaan et al, 2015). A similar finding was also reported from studies in Turkey (Saltoglu et al, 2015) and Poland (Nehring, 2015)

\section{Conclusion and Recommendations}

In conclusion, most elderly patients with diabetes mellitus have related complications, with no regular follow-up and inadequate foot care practices. Patients' foot self-care practices are influenced by their education, job, income, and smoking, as well as by disease duration. Adequate practices are reflected positively on feet condition, with better blood flow, sensation, and no neurological abnormalities. The study recommends more intensive training and education for elderly patients with diabetes in the care of their diabetes, including. The role of nursing in such educational programs is emphasized. Special attention should be directed to those with low socio-economic and educational levels. Further research is proposed to assess the impact of patient education interventions on the prevention of diabetes complications in the elderly.

\section{References}

[1] Al Sayah F., Soprovich A., Qiu W., Edwards A. L., and Johnson J. A. (2015): Diabetic Foot Disease, Self-Care and Clinical Monitoring in Adults with Type 2 Diabetes: The Alberta's Caring for Diabetes (ABCD) Cohort Study. Can J Diabetes. 2015 Aug 1. pii: S1499-2671(15)00467-0. doi: 10.1016/j.jcjd.2015.05.006. [Epub ahead of print.

[2] Al-Kaabi J. M., Al Maskari F., Cragg P., Afandi B., and Souid A. K. (2015): Illiteracy and diabetic foot complications. Prim Care Diabetes. 2015 May 28. pii: S1751-9918 (15)00070-4. doi: 10.1016/j.pcd.2015.04.008. [Epub ahead of print].

[3] Al-Rubeaan K., Al Derwish M., Ouizi S., Youssef A. M., Subhani S. N., Ibrahim H. M., and Alamri B. N. (2015): Diabetic foot complications and their risk factors from a large retrospective cohort study. PLoS One.; 10(5): e0124446. doi: 10.1371/journal.pone.0124446. eCollection 2015.

[4] Barr E. L., Browning C., and Lord S. R. (2007): Foot and leg problems are important determinants in functional status in community dwelling older people. Disab Rehabli J; 27: 917-23. 
[5] Biernacki P. J., Champagne M. T., Peng S., Maizel D. R., and Turner B. S. (2015): Transformation of Care: Integrating the Registered Nurse Care Coordinator into the Patient-Centered Medical Home. Popul Health Manag. 2015 Jan 29. [Epub ahead of print].

[6] Busetto L., Luijkx K., Huizing A., and Vrijhoef B. (2015): Implementation of integrated care for diabetes mellitus type 2 by two Dutch care groups: a case study. BMC Fam Pract.; 16(1): 105. doi: 10.1186/s12875-015-0320-z.

[7] Buysman E. K., Liu F., Hammer M., and Langer J. (2015): Impact of medication adherence and persistence on clinical and economic outcomes in patients with type 2 diabetes treated with liraglutide: a retrospective cohort study. Adv Ther.; 32(4): 34155. doi: 10.1007/s12325-015-0199-z. Epub 2015 Apr 2.

[8] Central Agency for public Mobilization and Statistics [CAMAS], (2011): Population Census of Egypt: Cairo; 28: 50.

[9] Chavan G. M., Waghachavare V. B., Gore A. D., Chavan V. M., Dhobale R. V., and Dhumale G. B. (2015): Knowledge about diabetes and relationship between compliance to the management among the diabetic patients from Rural Area of Sangli District, Maharashtra, India. J Family Med Prim Care.; 4(3): 439-43. doi: 10.4103/2249-4863.161349.

[10] Chellan G., Srikumar S., Varma A. K., Kumar H., and Bal A. (2012): Foot care practice -The key prevent diabetic foot ulcer in India. The Foot Journal; 22(6): 298-302.

[11] Desalu O. O., Salawu F. K., and Jimoh A. K. (2011): Diabetic foot care: self reported knowledge and practice among patients attending three tertiary hospitals in Nigeria. Ghana Medical Journal; 45(2): 60-65.

[12] Du Y. F., Ou H. Y., Beverly E. A., and Chiu C. J. (2014): Achieving glycemic control in elderly patients with type 2 diabetes: a critical comparison of current options. Clin Interv Aging; 9:1963-80.

[13] Groner C. (2010): Diabetes experts focus on foot ulcer recurrence lower extremity rev; 9: 43.

[14] Islam S., Harnarayan P., Cawich S. O., Budhooram S., Bheem V., Mahabir V., Ramsewak S., Aziz I., and Naraynsingh $V$. (2013): Epidemiology of diabetic foot infections in an eastern Caribbean population: a prospective study. Perm J.; 17(2): $37-$ 40. doi: $10.7812 / \mathrm{TPP} / 12-126$.

[15] Jiang Y., Wang X., Xia L., Fu X., Xu Z., Ran X., Yan L., Li Q., Mo Z., Yan Z., Ji Q., Li Q. (2015): A cohort study of diabetic patients and diabetic foot ulceration patients in China. Wound Repair Regen.; 23(2): 222-30. doi: 10.1111 /wrr.12263.

[16] Kangas M., Vikman I., Nyberg L., Korpelainen R., Lindblom J. and Jms T. (2011): Comparison of real-life accidental falls in older people with experimental falls inmiddle-aged test. Geriatrics; 67(8): 20-25.

[17] Khosravizade Tabasi H., Madarshahian F., Khoshniat Nikoo M., Hassanabadi M., and Mahmoudirad G. (2014): Impact of family support improvement behaviors on anti diabetic medication adherence and cognition in type 2 diabetic patients. J Diabetes Metab Disord.; 13(1): 113. doi: 10.1186/s40200-014-0113-2. eCollection 2014.

[18] Lauterbach S., Kostev K., and Kohlmann T. (2013): Prevalence of diabetic foot syndrome and its risk factors in the UK. J Wound Care; 19: 333-337.

[19] Lopez-Otin C., Blasco M. A., Partridge L., Serrano M., and Kroemer G. (2013): "The hallmarks of aging." Cell; 153(6): $1194-1217$
[20] Losby J. L., House M. J., Osuji T., O'Dell S. A., Mirambeau A. M., Elmi J., Chappelle E., and Schlueter D. F. (2015): Initiatives to Enhance Primary Care Delivery: Two Examples from the Field. Health Serv Res Manag Epidemiol.; 2. pii: 2333392814567352 .

[21] Louise B., and Russell (2009): Time requirements for diabetes self-management. Too much for many? Journal of Family Practice.

[22] Mayberry L. S., and Osborn C. Y. (2014): Dec Family involvement is helpful and harmful to patients' self-care and glycemic control. Patient Educ Couns.; 97(3): 418-25. doi: 10.1016 /j.pec.2014.09.011. Epub 2014 Sep 20.

[23] Mendes J. J., and Neves J. (2012): Diabetic Foot Infections: Current Diagnosis and Treatment. The Journal of Diabetic Foot Complications; 4, Issue 2(1): 26-45.

[24] Moxey P. W., Gogalniceanu P., and Hinchliffe R. J. (2011): Lower extremity amputations - a review of global variability in incidence. Diabet Med; 28: 1144-1153.

[25] Napolitano F., Napolitano P., and Angelillo I. F. (2015): Collaborative Working Group. Medication adherence among patients with chronic conditions in Italy. Eur J Public Health. 2015 Aug 11. pii: ckv147. [Epub ahead of print]

[26] National Foot Care Project [NFCP], (2003): Basic Foot Assessment Checklist. Available at website: http/ www.drsref.com.au/practice management/foot. assessment. Accessed on 10-12-2012.

[27] National Institute of Neurological Disorders and Strok [NINDS], (2011): Dementia information page. Senility Definition. Available at website http: //www.ninds.nih. gov/disorders/dementias/ dementia.htm accessed on 25-7-2013.

[28] Nehring P., Makowski A., Mrozikiewicz-Rakowska B, SobczykKopciot A., Ptoski R., and Karnafel W. (2015): Risk factors of diabetic foot of neuropathic origin in patients with type 2 diabetes. Endokrynol Pol.; 66(1): 10-4. doi: 10. 5603/EP.2015.0003.

[29] Nicolucci A., Cercone S., Chiriatti A., Muscas F., and Gensini G. (2015): A Randomized Trial on Home Telemonitoring for the Management of Metabolic and Cardiovascular Risk in Patients with Type 2 Diabetes. Diabetes Technol Ther.; 17(8): 563-70. doi: 10.1089/dia.2014.0355. Epub 2015 Jul 8.

[30] Peterman S. (2010): Steps toward Improved Foot Care to Prevent Diabetic Foot Ulcers. Nursing Consult Website. Available from http: //www.nursingconsult.com/das/stat/view/240435 2882/cup? nid $=203387$. accessed on $25-11-2014$

[31] Rajna O., and Alison S. (2006): Foot assessment in patients with diabetes Australian Family Physician; 35(6): 419-21.

[32] Rocha R. M., Zanetti M. L., and Snatos M. A. (2009): Behavior and knowledge: Basis for prevention of diabetic foot. Acta Paul Enferm; 22(1): 17-23.

[33] Saltoglu N., Yemisen M., Ergonul O., Kadanali A., Karagoz G., Batirel A., Ak O., Eraksoy H., Cagatay A., Vatan A., Sengoz G., Pehlivanoglu F., Aslan T., Akkoyunlu Y., Engin D., Ceran N., Erturk B., Mulazimoglu L., Oncul O., Ay H., Sargin F., Ozgunes N., Simsek F., Yildirmak T., Tuna N., Karabay O., Yasar K., Uzun N., Kucukardali Y., Sonmezoglu M., Yilmaz F., Tozalgan U., Ozer S., Ozyazar M2., KLIMIK Turkish Society, Diabetic Foot Study Group. (2015): Predictors for limb loss among patient with diabetic foot infections: an observational retrospective multicentric study in Turkey. Clin Microbiol Infect; 21(7): 659-64. doi: 10.1016/j.cmi.2015.03.018. Epub 2015 Apr 8 . 
[34] Shin S. A., Kim H., Lee K., Lin V., Liu G., and Shin E. (2015): Effects of diabetic case management on knowledge, selfmanagement abilities, health behaviors, and health service utilization for diabetes in Korea. Yonsei Med J.; 56(1): 24452. doi: 10.3349/ymj.2015.56.1.244.

[35] Skinner T. C., Bruce D. G., Davis T. M., and Davis W. A. (2014): Personality traits, self-care behaviours and glycaemic control in type 2 diabetes: the Fremantle diabetes study phase II. Diabet Med.; 31(4): 487-92. doi: 10.1111 /dme.12339. Epub 2013 Nov 18.

[36] Stuart B. C., Dai M., Xu J., Loh F. H., and Dougherty J. (2015): Does good medication adherence really save payers money? Med Care; 53(6): 517-23.
[37] Tol A., Shojaeezadeh D., Eslami A., Alhani F., Mohajeritehrani M., Baghbanian A., Sharifirad G. (2012a): Evaluation of self-care practices and relative components among type 2 diabetic patients. J Educ Health Promot.; 1: 19. doi: 10.4103/2277-9531.99219. Epub 2012 Jul 31.

[38] Tran D. T., Jorm L. R., Havard A., Harris M. F., Comino E. J. (2015): Variation in the use of primary care services for diabetes management according to country of birth and geography among older Australians. Prim Care Diabetes. 2015 Aug 1. pii: S1751-9918(15)00098-4. doi: 10.1016/j. pcd.2015.07.001. [Epub ahead of print]

[39] Wu L., Hou Q., Zhou Q., Peng F. (2015): Prevalence of risk factors for diabetic foot complications in a Chinese tertiary hospital. Int J Clin Exp Med.; 8(3): 3785-92. Collection 2015. 